\title{
Anogenital Distance in Turkish Newborns
}

\author{
Alev Oğuz Kutlu \\ Zubeyde Hanim Maternal Hospital, Department of Pediatric Endocrinology, Ankara, Turkey
}

Key words: Anogenital distance, newborn, Turkish

Conflict of interest: None declared

Received: 28.10.2011
Accepted: 22.11.2011

\section{Introduction}

We have measured anogenital distance (AGD) in 300 newborns delivered in Zubeyde Hanim Maternity Hospital in 2007. As in the study by Ozkan et al (1), we also used a sliding caliper for the measurements; however, in the manuscript by Ozkan et al (1), it was mentioned as tape, which needs correction.

The results of both Dr Ozkan's study and ours seem similar. We could not give the results of measurements of anus-anterior penis base distance in male newborns and anus-clitoris base (AC) distance in female newborns. The AGD1 distance in male newborns in our study and in Ozkan et al's study were $41.8 \pm 4.9 \mathrm{~mm}$ and $56 \pm 1 \mathrm{~mm}$, respectively. The AC distance in female newborns in our study and in Ozkan et al's study were $35.04 \pm 3.34 \mathrm{~mm}$ and $30.2 \pm 0.2 \mathrm{~mm}$, respectively (unpublished data). Positive correlation of AGD1 and $\mathrm{AC}$ with length, head circumference and weight was also found in our study. However, no correlation was found for both the distance from the posterior base of the scrotum to the anus (ASD) in male newborns and the distance from the anus to the fourchette (AF) with same parameters. Our data suggests that the measurement of AGD1 is more reliable than ASD as the posterior border of the scrotum is an anthropometry. Romano-Riquer et al (2) also proposed that the measurement of AGD1 is more reliable than other measurement methods of AGD.

The percentile values were calculated for AGD of male and female newborns in our study.

For female newborns, the $3^{\text {rd }}, 5^{\text {th }}, 10^{\text {th }}, 25^{\text {th }}, 50^{\text {th }}, 75^{\text {th }}$, 90th, 95th and $97^{\text {th }}$ percentile values for AF distance were 
found as $8.98 m m-9.14 m m-9.49 m m-11.40 m m-13.20$ $\mathrm{mm}-15.06 \mathrm{~mm}-16.30 \mathrm{~mm}$ and $20.93 \mathrm{~mm}$, respectively.

Percentile values for AC distance were $29.12 \mathrm{~mm}-29.82$ mm -30.94 mm - $33.00 m m-34.50$ mm - 37.20 mm - 39.39 $\mathrm{mm}$ and $42.19 \mathrm{~mm}$, respectively.

For male newborns, the $3 \mathrm{rd}, 5^{\text {th }}, 10^{\text {th }}, 25^{\text {th }}, 50^{\text {th }}, 75^{\text {th }}$ 90th, 95th and $97^{\text {th }}$ percentile values for ASD distance were found as $18.03 \mathrm{~mm}$ - $18.67 \mathrm{~mm}-20.18 \mathrm{~mm}$ - $22.57 \mathrm{~mm}$ $25.16 \mathrm{~mm}-29.20 \mathrm{~mm}-32.28 \mathrm{~mm}$ and $36.81 \mathrm{~mm}$, respectively.

Percentile values for AGD1 distance were $32.89 \mathrm{~mm}$ $33.80 \mathrm{~mm}$ - $35.46 \mathrm{~mm}$ - $38.85 \mathrm{~mm}$ - $40.95 \mathrm{~mm}$ - $45.02 \mathrm{~mm}$ - $48.20 \mathrm{~mm}$ and $51.52 \mathrm{~mm}$, respectively.

I measured the stretched penile length (SPL) and found $3.77 \pm 0.35 \mathrm{~cm}$ as the mean value in a previous study on 514 newborns (3) and same parameter in the study by Ozkan et al (1) was reported to be $3.2 \pm 0.2 \mathrm{~cm}$. Ozkan et al (1) used caliper for the measurement of SPL, whereas I used spatula. It can be considered that the difference in values could be the result of different measurement techniques. In our study, the SPL was found a bit longer than in some studies, but similar result was found in a study by Lian et al (4). In this study, SPL of Asian newborns was measured to be $3.6 \pm 0.4 \mathrm{~cm}$ (4).

\section{References}

1. Ozkan B, Konak B, Cayir A, Konak M. Anogenital Distance in Turkish Newborns. J Clin Res Pediatr Endocrinol 2011;3:122125

2. Romano-Riquer SP, Hernandez-Avila M, Gladen BC,CupulUicab LA, Longnecker MP. Reliability and determinants of anogenital distance and penis dimensions in male newborns from Chiapas, Mexico. Pediatr Perinat Epidemiol 2007;21:219-228.

3. Oguz Kutlu A. Normative data for penile length in Turkish newborns. J Clin Res Ped Endocrinol 2010;2:107-110.

4. Lian WB, Lee WR, Ho LY. Penile length of newborns in Singapore. J Pediatr Endocrinol Metab 2000;13:55-62. 